Bài báo khoa học

\title{
Đánh giá sự phân bố nồng độ bụi PM2.5 tại khu vực TP. HCM bằng công nghệ viễn thám-một số kết quả ban đầu
}

\author{
Trần Quang Trà ${ }^{1}$, Nguyễn Phúc Hiếu ${ }^{2}$, Đào Nguyên Khôi ${ }^{1, *}$ \\ ${ }^{1}$ Khoa Môi Trường, Trường ĐH Khoa Học Tự Nhiên - ĐHQG Tp.HCM; \\ tqtra@hcmus.edu.vn;dnkhoi@hcmus.edu.vn \\ ${ }^{2}$ Công ty TNHH ERM Việt Nam; phuchieu50@gmail.com \\ * Tác giả liên hệ: dnkhoi@hcmus.edu.vn; Tel.: +84-989370987
}

Tóm tắt: Trong thời gian gần đây, ô nhiễm bụi mịn $\left(\mathrm{PM}_{2.5}\right)$ đã trở thành một trong những vấn đề môi trường đáng quan tâm nhất tại các khu đô thị ở các nước đang phát triển, trong đó có Việt Nam. Thành phố Hồ Chí Minh được biết đến là một trung tâm kinh tế lớn của Việt Nam, chiếm khoảng 23\% GDP của cả nước (2019), đã chịu ảnh hưởng rất lớn của ô nhiễm không khí do sự phát triển công nghiệp và phát thải từ hoạt động giao thông. Mục tiêu của nghiên cứu này là ước tính sự phân bố không gian nồng độ bụi $\mathrm{PM}_{2.5}$ trên địa bàn thành phố tại một số thời điểm trong giai đoạn 2015-2020 bằng việc sử dụng dữ liệu LANDSAT $8 \mathrm{OLI} /$ TIRS. Trong nghiên cứu này, giá trị phản xạ khí quyển từ ảnh vệ tinh và dữ liệu quan trắc bụi $\mathrm{PM}_{2.5}$ từ mặt đất được sử dụng để thiết lập mô hình tương quan hồi quy để tính toán nồng độ bụi $\mathrm{PM}_{2.5}$ cho khu vực nghiên cứu. Mô hình đã cho ra kết quả tốt trong việc tính toán nồng độ bụi $\mathrm{PM}_{2.5}$ với $\mathrm{R}^{2}>0,79$ và sai số $\mathrm{RMSE}=2,3745 \mu \mathrm{g} / \mathrm{m}^{3}$. Trên cơ sở đó, nồng độ bụi $\mathrm{PM}_{2.5}$ được thiết lập để đánh giá đặc điểm phân bố của chúng và nhận diện các khu vực có mức độ ô nhiễm cao tại các thời điểm ghi nhận được. Kết quả này sẽ cung cấp thông tin hữu ích cho các nhà quản lý chất lượng không khí tại địa phương.

Từ khóa: $\mathrm{PM}_{2.5}$; Ô nhiễm không khí; LANDSAT 8; Thành phố Hồ Chí Minh; Viễn thám.

\section{Mở đầu}

Ô nhiễm bụi mịn $\mathrm{PM}_{2.5}$ đã và đang trở thành một vấn đề lớn tại các khu đô thị [1-3]. Thuật ngữ $\mathrm{PM}_{2.5}$ có thể được hiểu là một hỗn hợp các hạt rắn và các giọt chất lỏng lơ lửng, có đường kính khí động học nhỏ hơn 2,5 $\mu \mathrm{m}$ [4]. Chúng gây ảnh hưởng nghiêm trọng đến sức khỏe con người, đặc biệt với các bệnh liên quan đến đường hô hấp và tim mạch, thậm chí gây tử vong $[5,6]$. Thành phố Hồ Chí Minh $(\mathrm{Tp}$. HCM) là khu vực đi đầu cả nước về tốc độ đô thị hóa với mật độ dân số cao [7], lượng phương tiện tham gia giao thông dày đặc cũng như số lượng lớn các khu công nghiệp [8] dẫn đến sự suy giảm chất lượng không khí xung quanh, trong đó đáng kể là bụi $\mathrm{PM}_{2.5}$. Do đó, quan trắc và thành lập bản đồ phân bố bụi $\mathrm{PM}_{2.5}$ là nhiệm vụ cấp thiết nhằm phục vụ công tác kiểm soát ô nhiễm bụi $\mathrm{PM}_{2.5}$.

Giám sát nồng độ bụi $\mathrm{PM}_{2.5}$ dựa vào dữ liệu quan trắc cho kết quả chính xác cao, tuy nhiên phương pháp này còn hạn chế về mặt không gian do bị giới hạn bởi số lượng các điểm quan trắc. Các nghiên cứu gần đây đã cho thấy tính hữu dụng của dữ liệu ảnh vệ tinh trong việc thành lập bản đồ phân vùng và giám sát ô nhiễm không khí [9-14]. Liên quan đến bựi $\mathrm{PM}_{2.5}$, nghiên cứu [10] ứng dụng viễn thám để xác định hàm lượng bụi $\mathrm{PM}_{2.5}$ ở Trung Quốc dựa trên tương quan với đặc điểm độ dày quang học sol khí (AOD-Aerosol Optical Depth) và kết quả cho thấy mức độ tương quan khá tốt ở dữ liệu tháng và năm. Một nghiên cứu tương tự [11] cũng cho thấy mối tương quan giữa hàm lượng bụi $\mathrm{PM}_{2.5}$ và $\mathrm{AOD}$ và tìm thấy được sự ảnh hưởng của điều kiện khí tượng và mùa mối quan hệ giữa nồng độ bụi $\mathrm{PM}_{2.5}$ và tán xạ ngược bề mặt. Bên cạnh nghiên cứu về mối quan hệ giữa bụi $\mathrm{PM}_{2.5}$ và $\mathrm{AOD}$, nghiên 
cứu [12] xác định mối quan hệ giữa bụi $\mathrm{PM}_{2.5}$ và phản xạ khí quyển từ các kênh ảnh của ảnh vệ tinh Landsat 8 OLI và TIRS. Kết quả cho thấy bụi $\mathrm{PM}_{2.5}$ có mối tương quan với các kênh ảnh 1,2 và 5 , và thành lập được bản đồ phân bố bụi $\mathrm{PM}_{2.5}$ cho thành phố Delhi (Ấn Độ).

Việc sử dụng công nghệ viễn thám kết hợp dữ liệu từ mặt đất để nghiên cứu về bụi cũng thu hút được sự chú ý của các nhà khoa học trong nước trong những năm gần đây. Nghiên cứu [13] sử dụng ảnh LANDSAT/ETM+ dựa trên tương quan-hồi quy giữa giá trị AOT tính toán trên ảnh và số đo mặt đất từ trạm quan trắc để mô phỏng phân bố bụi $\mathrm{PM}_{10}$ khu vực nội thành $\mathrm{Tp} . \mathrm{HCM}$; [14] phân tích tương quan giữa $\mathrm{AOD}$ từ ảnh vệ tinh MODIS và hàm lượng bụi $\mathrm{PM}_{2.5}$ từ mô hình GEOS-Chem (hàm lượng bụi $\mathrm{PM}_{2.5}$ được xác định bằng tổng $\mathrm{SO}_{4}$, NIT (sulfur nitrate vô cơ), $\mathrm{NH}_{4}$, OCP (Carbon hữu cơ), SOA (sol khí hữu cơ thứ cấp), SALA (sol khí chứa muối biển)) để giám sát thay đổi hàm lượng bụi $\mathrm{PM}_{2.5}$ Ở miền Bắc Việt Nam. Nhìn chung, các nghiên cứu trên đã cho thấy viễn thám tỏ ra là một công cụ hiệu quả trong việc giám sát bụi $\mathrm{PM}_{2.5}$ theo phân bố không gian và thời gian, trong đó ảnh vệ tinh LANDSAT 8 là nguồn dữ liệu ảnh miễn phí mới và có độ phân giải không gian phù hợp.

Nhìn chung, các nghiên cứu đề cập ở trên cho thấy được thế mạnh của viễn thám trong đánh giá và thành lập bản đồ phân bố nồng độ bụi mịn. Riêng với khu vực $T p$. $H C M$, vẫn chưa có nghiên cứu về ứng dụng viễn thám để tính toán nồng độ bụi $\mathrm{PM}_{2.5}$, các nghiên cứu thực hiện chỉ tập trung vào bụi $\mathrm{PM}_{10}$ [13]. Mục tiêu của nghiên cứu này là xác định mối tương quan giữa phản xạ khí quyển từ ảnh vệ tinh LANDSAT 8 và nồng độ bụi $\mathrm{PM}_{2.5}$ từ các trạm quan trắc, từ đó thiết lập bản đồ phân bố nồng độ bụi $\mathrm{PM}_{2.5} \mathrm{khu}$ vực Tp. $\mathrm{HCM}$ vào một số thời kỳ. Kết quả nghiên cứu được mong chờ sẽ đánh giá được mức độ ô nhiễm ở khu vực nghiên cứu, phục vụ cho công tác quản lý và kiểm soát ô nhiễ்m không khí tại thành phố Hồ Chí Minh.

\section{Khu vực nghiên cứu}

Thành phố Hồ Chí Minh nằm trong vùng nhiệt đới gió mùa cận xích đạo với nhiệt độ cao đều trong năm và có hai mùa mưa-khô rõ rệt tác động làm chi phối môi trường cảnh quan sâu sắc. Khu vực nghiên cứu tập trung chủ yếu vào các quận/ huyện nội thành như Error! Reference source not found.. Theo tài liệu quan trắc tại các quận/ huyện nội thành nhiều năm cho thấy lượng bức xạ dồi dào, trung bình khoảng $140 \mathrm{Kcal} / \mathrm{cm}^{2} / \mathrm{năm}$. Số giờ nắng trung bình/tháng 160-270 giờ. Nhiệt độ không khí trung bình $27^{\circ} \mathrm{C}$. Lượng mưa cao, bình quân $1949 \mathrm{~mm} /$ năm [15]. Về gió, Tp. HCM chịu ảnh hưởng bởi hai hướng gió chính và chủ yếu là gió mùa Tây-Tây Nam (từ tháng 6 đến tháng 10 , tốc độ trung bình $3,6 \mathrm{~m} / \mathrm{s}$ ) và BắcĐông Bắc (từ tháng 11 đến tháng 2 , tốc độ trung bình $2,4 \mathrm{~m} / \mathrm{s}$ ).

Đặc điểm giao thông đô thị của Tp. HCM chủ yếu tập trung vào đường bộ với tổng chiều dài đường bộ trong Thành phố là $3670 \mathrm{~km}$ và đây cũng là phương thức chủ đạo giải quyết nhu cầu giao thông vận tải đô thị. Theo thống kê của Sở Giao thông Vận tải Tp. HCM năm 2019, Tp. HCM đang quản lý khoảng 8,05 triệu phương tiện giao thông (gồm gần 755.500 ô tô và gần 7,3 triệu xe môtô) và một số lượng rất lớn các phương tiện mang biển số các tỉnh hoạt động trên địa bàn [16]. Vào giờ cao điểm tại các trục đường chính đều có số phương tiện lưu thông rất lớn.

\section{Dũ liệu và phương pháp nghiên cứu}

\subsection{Dũ liệu}

Nghiên cứu sử dụng ảnh vệ tinh đa thời gian Landsat 8 OLI/TIRS được thu thập từ Cục Khảo sát Địa chất Hoa Kỳ (USGS) (www. glovis.usgs.gov) trong giai đoạn từ năm 2015 đến năm 2020 (Bảng 1) [17]. Tiêu chí lựa chọn ảnh là chọn các ảnh trong thời gian mùa khô và ảnh có chất lượng tốt (ảnh không bị sọc và không có lỗi cảm biến). Các ảnh chọn lựa có thời 
gian chụp vào khoảng 9-10 giờ sáng. Ảnh vệ tinh sử dụng bộ cảm OLI/TIRS; vị trí cột/dòng là 125/52 với độ phân giải không gian 30m x 30m, hệ tọa độ UTM-48N.

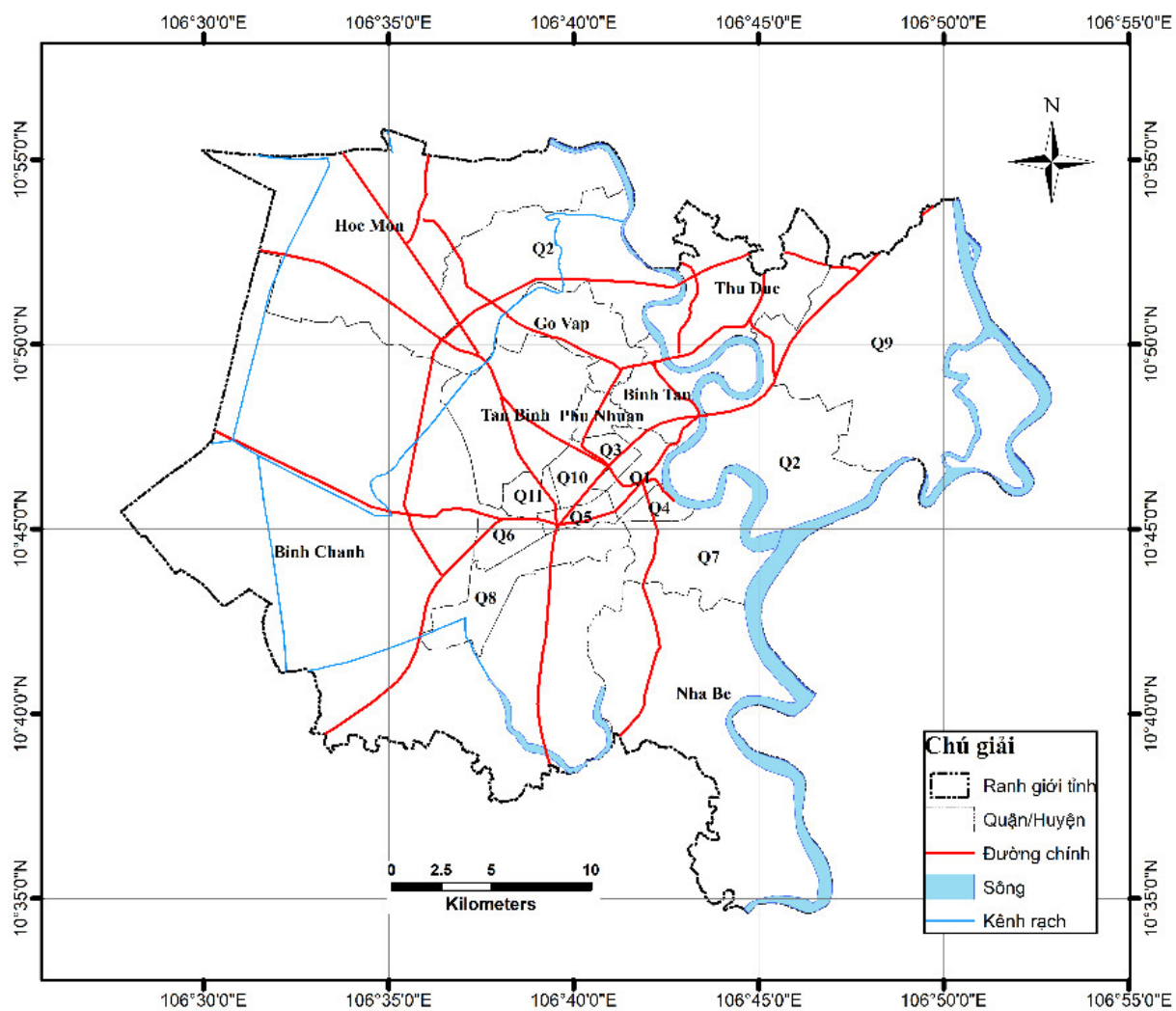

Hình 1. Khu vực nghiên cứu-nội thành Tp. HCM.

Bảng 1. Dữ liệu ảnh vệ tinh dùng trong nghiên cứu.

\begin{tabular}{cccc}
\hline STT & Thời gian & STT & Thời gian \\
\hline 1 & $24 / 01 / 2015$ & 10 & $18 / 03 / 2017$ \\
2 & $09 / 02 / 2015$ & 11 & $12 / 10 / 2017$ \\
3 & $13 / 03 / 2015$ & 12 & $31 / 12 / 2017$ \\
4 & $29 / 3 / 2015$ & 13 & $31 / 10 / 2018$ \\
5 & $11 / 01 / 2016$ & 14 & $02 / 12 / 2018$ \\
6 & $28 / 02 / 2016$ & 15 & $19 / 01 / 2019$ \\
7 & $29 / 01 / 2017$ & 16 & $07 / 02 / 2020$ \\
8 & $14 / 02 / 2017$ & 17 & $23 / 02 / 2020$ \\
9 & $01 / 03 / 2017$ & 18 & $26 / 03 / 2020$ \\
\hline
\end{tabular}

Bên cạnh đó, dữ liệu bụi $\mathrm{PM}_{2.5}$ quan trắc được thu thập từ các trạm quan trắc tự động tại Trường Đại học Khoa học Tự nhiên (ĐHQG-HCM) và tại Lãnh sự quán Hoa Kỳ. Ngoài ra, nghiên cứu sử dụng thêm một số điểm quan trắc tại Sở Khoa học Công nghệ, Cư xá Đô Thành, Thảo Cầm viên, và Thủ Thiêm giai đoạn 2017-2019. Mẫu bụi tại các điểm quan trắc này được thu trên bộ lọc thạch anh (được tiền xử lý) bằng cách sử dụng bộ lấy mẫu IMPACT, với tốc độ lấy mẫu $\mathrm{v}=10 \mathrm{~L} /$ phút. Mẫu khí sẽ đi qua 2 tấm lọc $(37 \mathrm{~mm}$ và $47 \mathrm{~mm})$ : mẫu khí được hút qua impactor để phân tách kích thước hạt $(2,5 \mu \mathrm{m})$, sau đó mẫu khí được đưa liên tục qua tấm lọc thứ 2 để thu lượng bụi mịn có kích thước $\leq 2,5 \mu \mathrm{m}$. Thể tích khí được ghi lại bằng đồng hồ đo khí khô. Khối lượng $\mathrm{PM}_{2.5}$ được cân bằng cân vi lượng với độ nhạy $10^{-}$ ${ }^{6} \mathrm{~g}$ [18]. Dữ liệu quan trắc được trình bày trong Bảng 2 . Vị trí các điểm quan trắc được thể hiện trong Hình 2. 
Bảng 2. Dữ liệu bụi quan trắc dùng trong nghiên cứu [18].

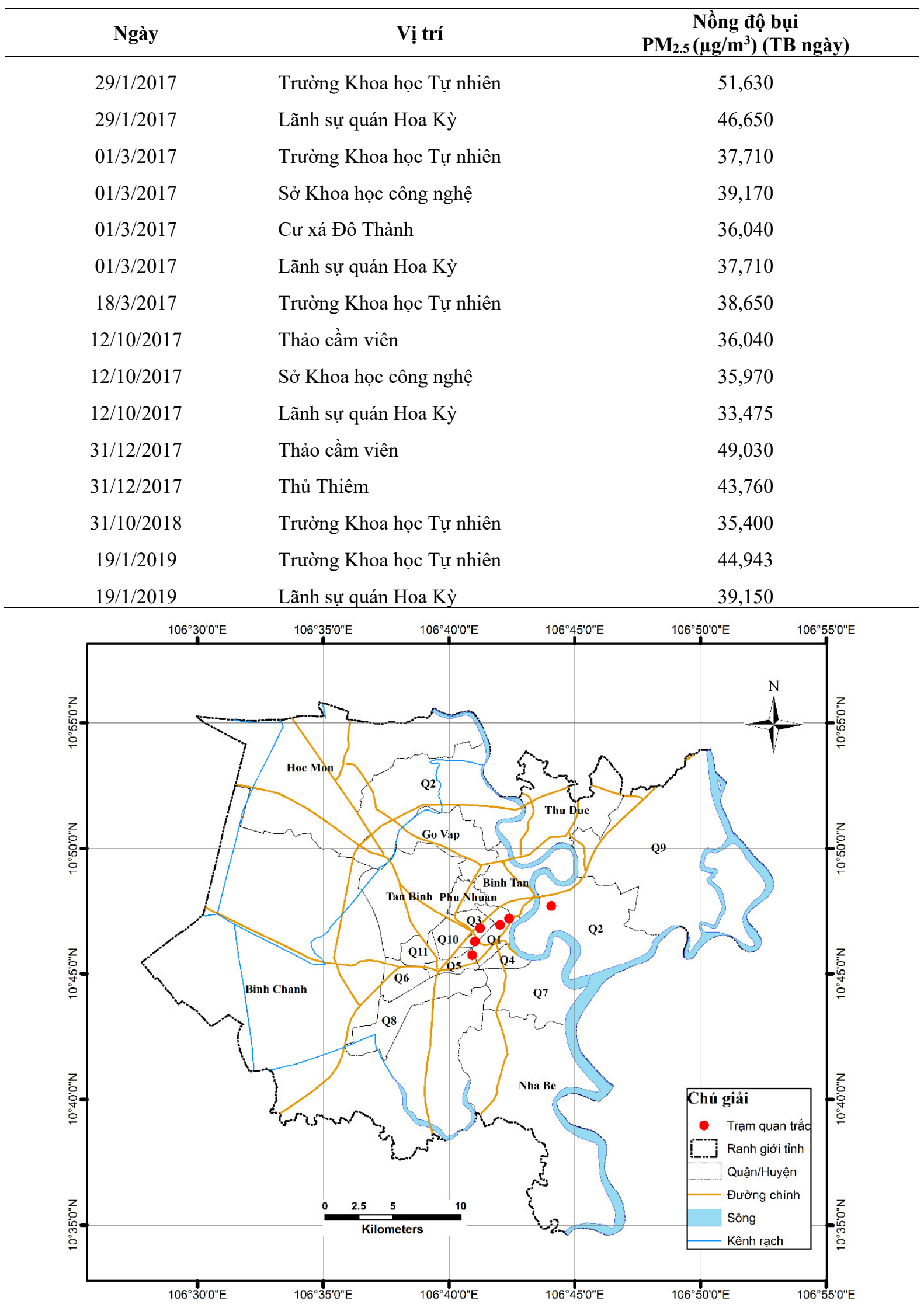

Hình 2. Vị trí các điểm quan trắc bụi. 


\subsubsection{Phương pháp nghiên cứu}

Quá trình nghiên cứu được thực hiện theo trình tự của sơ đồ mô tả trên Hình 2, bao gồm các bước sau:

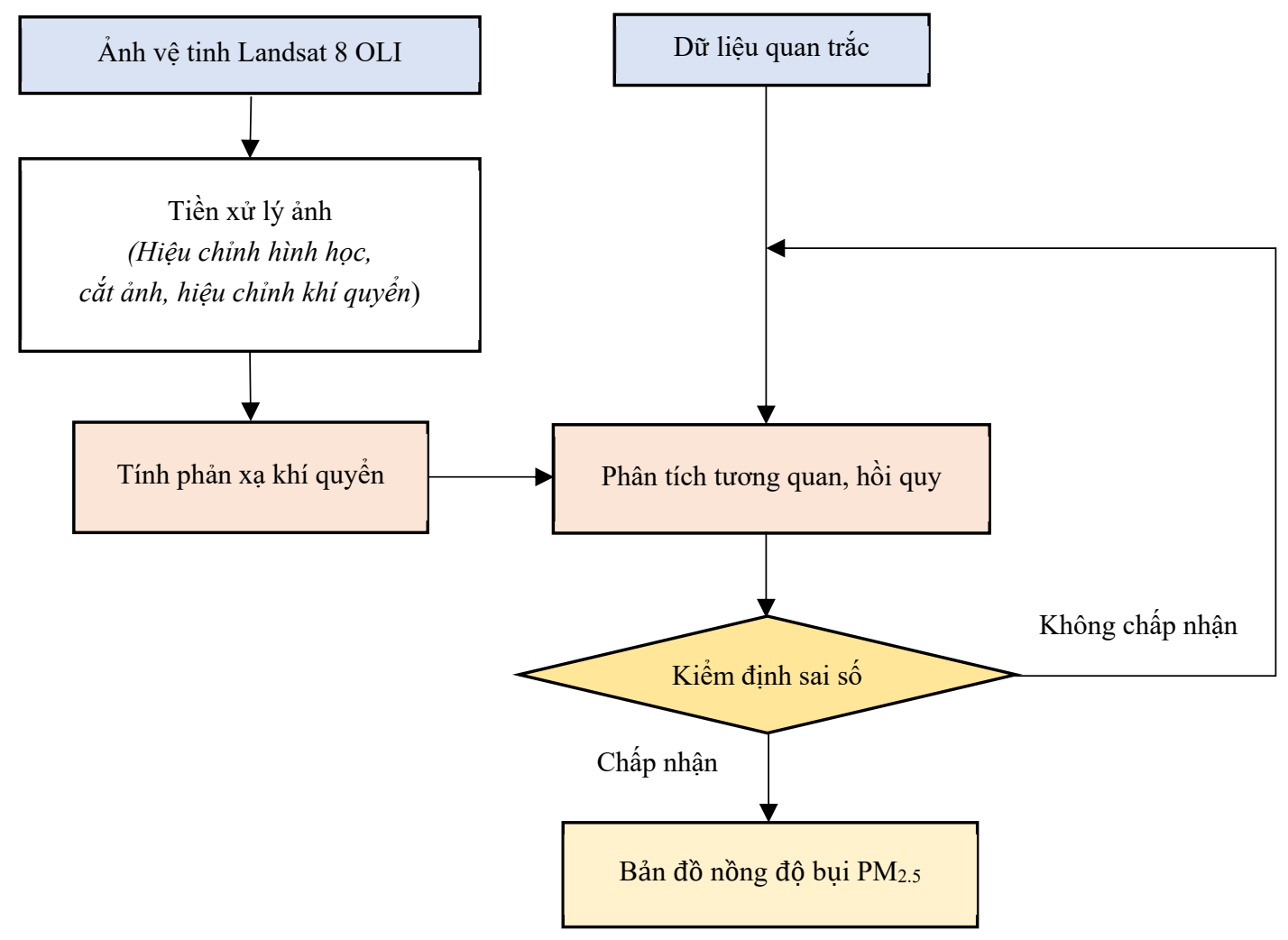

Hình 3. Sơ đồ khối các bước thực hiện nghiên cứu.

\section{- Hiệu chỉnh hình hoc và cắt ảnh}

Trước quá trình phân tích, giải đoán, ảnh vệ tinh cần được nắn chỉnh hình học để hạn chế sai số vị trí và chênh lệch địa hình, sao cho hình ảnh gần với bản đồ địa hình ở phép chiếu trực giao nhất. Kết quả giải đoán phụ thuộc rất nhiều vào độ chính xác của ảnh. Khu vực nghiên cứu nằm trên một tấm ảnh có cột/hàng là 125/052, sau khi tải tiến hành nắn chỉnh hình học và cắt theo ranh giới khu vực nghiên cứu.

\section{- Hiệu chinh khí quyển}

Để loại bỏ những ảnh hưởng của khí quyển đến chất lượng ảnh cần chuyển đổi giá trị số của ảnh sang giá trị bức xạ tại đầu thu (tại đỉnh của khí quyển), sau đó chuyển bức xạ đầu thu về bức xạ mặt đất và hiệu chỉnh khí quyển. Chuyển đổi giá trị số sang giá trị bức xạ phổ tại đỉnh khí quyển theo công thức được cung cấp bởi USGS [17]:

$$
L_{\lambda}=M_{L} \cdot Q_{c a l}+A_{L}
$$

Trong đó $\mathrm{L}_{\lambda}$ giá trị bức xạ phổ; $\mathrm{M}_{\mathrm{L}}, \mathrm{A}_{\mathrm{L}}$ tương ứng với hệ số chuyển đổi, được cung cấp

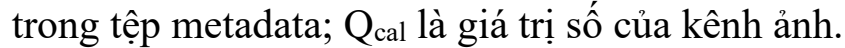

Chuyển đổi giá trị số sang giá trị phản xạ phổ tại đỉnh khí quyển theo công thức được cungcấp bởi USGS:

$$
\rho \lambda=\frac{\mathrm{MP} * \mathrm{Qcal}+\mathrm{AP}}{\cos \theta_{\mathrm{SZ}}}
$$

Trong đó $\rho \lambda$ là giá trị phản xạ đỉnh khí quyển; $M_{P}, A_{P}$ là các hệ số thay đổi tỷ lệ phản xạ của kênh ảnh được cung cấp từ tệp metadata; $\theta_{\mathrm{SZ}}$ là góc thiên đỉnh cục bộ $\left(\theta_{\mathrm{SZ}}=90^{\circ}\right.$ $\left.\theta_{\mathrm{SE}}\right) ; \theta_{\mathrm{SE}}$ là góc tới mặt trời. 
Giá trị phản xạ tại bề mặt đất cần được hiệu chỉnh để loại trừ đi các yếu tố sai số do các aerosol gây ra bởi quá trình tán xạ, hấp thụ. Phản xạ mặt đất $(\rho)$ được tính theo công thức sau:

$$
\rho=\frac{\pi \times\left(L_{\lambda}-L_{P}\right) \times d^{2}}{\left.T_{V} \times\left[\left(E S U N_{\lambda} \times \cos \theta_{S Z} \times T_{Z}\right)+E_{d o w n}\right)\right]}
$$

Trong đó $\mathrm{L}_{P}$ là bức $x a ̣$ đường truyền; $\mathrm{T}_{V}$ là hàm truyền bức xạ qua khí quyển từ bề mặt trái đất về đầu thu; $\mathrm{T}$ là hàm truyền bức xạ qua khí quyển từ mặt trời về bề mặt Trái Đất;

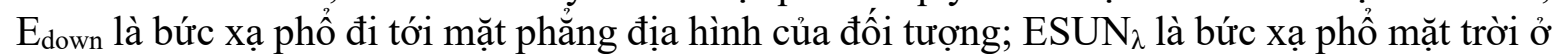
mặt phẳng địa hình vuông góc với tia sáng mặt trời; $\mathrm{d}$ là khoảng cách từ trái đất đến mặt trời.

Để hiệu chỉnh khí quyển, nghiên cứu này sử dụng phương pháp trừ đối tượng tối $(D O S$ Dark Object Subtraction) [19]. Đối với ảnh Landsat 8:

$$
\mathrm{L}_{\mathrm{P}}=\mathrm{L}_{\text {min }}-0,01 \times \frac{\mathrm{T}_{\mathrm{V}} \times\left[\left(\mathrm{ESUN}_{\lambda} \times \cos \theta_{\mathrm{SZ}} \times \mathrm{T}_{\mathrm{Z}}\right)+\mathrm{E}_{\mathrm{down}}\right]}{\pi \times \mathrm{d}^{2}}
$$

Trong đó $\mathrm{L}_{\text {min }}$ là giá trị bức xạ phổ bé nhất của kênh ảnh (lấy từ tệp metadata).

Với phương pháp DOS phụ thuộc vào việc xác định các thông số $T_{V}, T_{Z}$ và $E_{\text {down }}$ mà chia ra các phương pháp khác nhau, có độ chính xác khác nhau. Nghiên cứu này sử dụng phương pháp DOS1, trong đó các thông số: $\mathrm{T}_{\mathrm{V}}=1 ; \mathrm{T}_{\mathrm{Z}}=1 ; \mathrm{E}_{\mathrm{down}}=0$ [19]. Như vậy, bức xạ đường truyền được tính theo công thức:

$$
L_{P}=L_{\text {min }}-0,01 x \frac{\operatorname{ESUN}_{\lambda} \times \cos \theta_{S Z}}{\pi \times d^{2}}
$$

Từ đó, phản xạ mặt đất được tính theo công thức sau:

$$
\rho=\frac{\pi x\left(L_{\lambda}-L_{P}\right) \times d^{2}}{\operatorname{ESUN}_{\lambda} \times \cos \theta_{S Z}}
$$

- Tính toán giá trị phản xạ khí quyển:

Giá trị phản xạ đỉnh khí quyển bằng tổng bức xạ mặt đất và phản xạ khí quyển, do đó giá trị phản xạ khí quyển được tính theo công thức [12]:

$$
R_{a t m}=R_{s}-R_{r}
$$
bề mặt.

Trong đó $\mathrm{R}_{\mathrm{atm}}$ là phản xạ khí quyển; $\mathrm{R}_{\mathrm{s}}$ là phản xạ ghi nhận bởi vệ tinh; $\mathrm{R}_{\mathrm{r}}$ là phản xạ từ

- Phân tích hồi quy-tuoong quan:

Nghiên cứu tìm mối tương quan giữa giá trị phản xạ khí quyển và nồng độ bụi $\mathrm{PM}_{2.5}$ trong không khí dựa trên hệ số tương quan Pearson và ước lượng nồng độ bụi theo phương trình hồi quy [16]:

$$
P M_{2.5}=a_{0}+a_{1} R_{1}+a_{2} R_{2}+a_{3} R_{3}+\cdots
$$

Trong đó $\mathrm{R}_{\mathrm{i}}$ là phản xạ khí quyển tương ứng với kênh ảnh khác nhau; $\mathrm{a}_{\mathrm{i}}$ là hệ số xác định từ thực nghiệm.

- Tính toán sai số:

Sai số được tính toán giữa giá trị bụi ước tính từ phương trình và giá trị bụi thực đo:

$$
\mathrm{RMSE}=\sqrt{\frac{\sum(P \text { ước tính-P thực đo })^{2}}{N}}
$$

Trong đó $\mathrm{P}$ ước tính là giá trị bụi ước tính từ phương trình; $\mathrm{P}$ thực đo là giá trị bụi quan trắc; $\mathrm{N}$ là số mẫu.

Hệ số hiệu quả mô hình Nash-Sutcliffe Efficiency:

$$
\mathrm{NSE}=1-\left(\frac{\sum_{i=1}^{n}(P \text { thực đo }-P \text { ước tính })^{2}}{\sum_{i=1}^{n}(P \text { thực đo }-P \text { trung bình })^{2}}\right)
$$

Ngoài ra, nghiên cứu cũng xem xét: mức xác suất ý nghĩa (Sig.F), giá trị này phải nhỏ hơn 0,05 thì mô hình có ý nghĩa; $\mathrm{R}^{2}$ hiệu chỉnh; sai số chuẩn ước lượng. 


\section{Kết quả và thảo luận}

\subsection{Mối tương quan giữa bụi $P M_{2.5}$ và hệ số phản xạ khí quyển}

Tán xạ khí quyển khi năng lượng Mặt Trời đi qua diễn ra trong dải phổ nhìn thấy đến cận hồng ngoại [13], do đó các kênh ảnh $1,2,3,4$ và 5 trong dải phổ này sẽ được sử dụng để tìm ra mối quan hệ với các hạt bụi lơ lửng. Trước khi tiến hành xây dựng phương trình hồi quy, nghiên cứu kiểm tra sự tương quan giữa hệ số phản xạ khí quyển của từng kênh ảnh với nồng độ bụi $\mathrm{PM}_{2.5}$ quan trắc. Hệ số tương quan Pearson giữa hệ số phản xạ khí quyển và nồng độ bụi tại mặt đất được thể hiện trong Bảng 3 .

Bảng 3. Hệ số tương quan Pearson giữa hệ số phản xạ khí quyển và nồng độ bụi.

\begin{tabular}{|c|c|c|c|c|c|}
\hline Kênh & Kênh 1 & Kênh 2 & Kênh 3 & Kênh 4 & Kênh 5 \\
\hline Nồng độ bụi & 0,865 & 0,863 & 0,856 & 0,815 & 0,661 \\
\hline
\end{tabular}

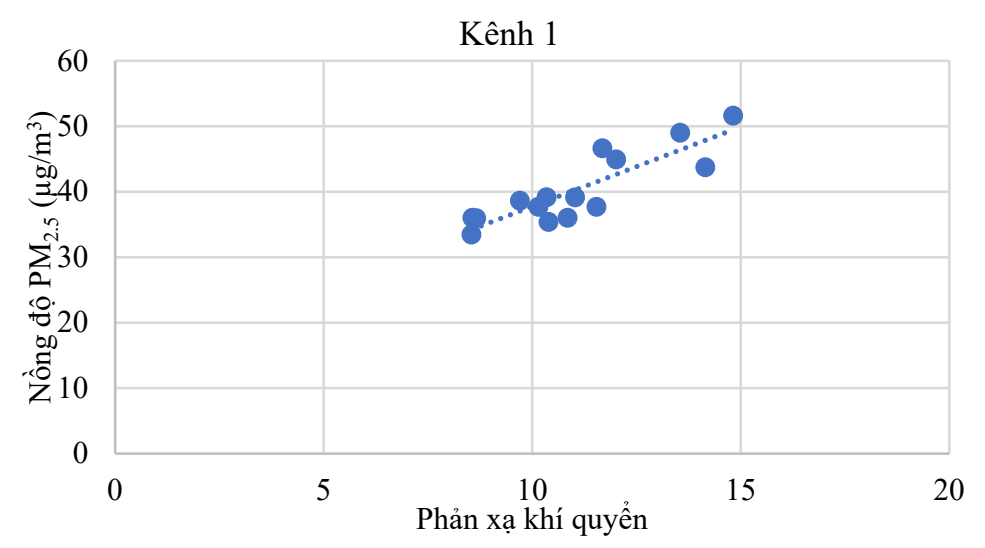

Hình 4. Đồ thị tương quan giữa nồng độ bụi $\mathrm{PM}_{2.5}$ và giá trị phản xạ khí quyển kênh 1 .

Như vậy, hệ số phản xạ khí quyển của các kênh và nồng độ bụi quan trắc có sự tương quan khá tốt với nhau. Dựa vào mối quan hệ giữa nồng độ bụi với hệ số phản xạ khí quyển của các kênh ảnh $1-5$, kết quả phương trình hồi quy và giá trị hệ số xác định bội $\mathrm{R}^{2}$ và sai số RMSE được trình bày trên Bảng 3 . Kết quả cho thấy các phương trình đều có giá trị sai số RMSE nằm trong khoảng cho phép và mức ý nghĩa xác suất phù hợp.

Bảng 4. Kết quả hồi quy giữa hệ số phản xạ khí quyển và nồng độ bụi tại mặt đất.

\begin{tabular}{|c|c|c|c|c|c|c|c|c|c|}
\hline STT & & & Kênh 1 & Kênh 2 & Kênh 3 & Kênh 4 & Kênh 5 & NSE & $\begin{array}{l}\text { RMSE } \\
\left(\mu \mathrm{g} / \mathrm{m}^{3}\right)\end{array}$ \\
\hline 1 & $\mathrm{PM}_{2.5}=$ & 13,436 & $+2,4329 \mathrm{R}_{1}$ & & & & & 0,7478 & 2,6655 \\
\hline 2 & $\mathrm{PM}_{2.5}=$ & 15,640 & & $+2,3295 \mathrm{R}_{2}$ & & & & 0,7451 & 2,6801 \\
\hline 3 & $\mathrm{PM}_{2.5}=$ & 15,940 & & & $+2,6762 \mathrm{R}_{3}$ & & & 0,7319 & 2,7484 \\
\hline 4 & $\mathrm{PM}_{2.5}=$ & 17,439 & & & & $+3,0987 \mathrm{R}_{4}$ & & 0,6641 & 3,0766 \\
\hline 5 & $\mathrm{PM}_{2.5}=$ & 16,365 & & & & & $+4,1141 \mathrm{R}_{5}$ & 0,4373 & 3,9819 \\
\hline 6 & $\mathrm{PM}_{2.5}=$ & 13,2664 & $+2,6277 \mathrm{R}_{1}$ & $-0,1871 R_{2}$ & & & & 0,7479 & 2,6655 \\
\hline 7 & $\mathrm{PM}_{2.5}=$ & 13,3276 & $+2,5648 \mathrm{R}_{1}$ & & $-0,1480 \mathrm{R}_{3}$ & & & 0,7479 & 2,6653 \\
\hline 8 & $\mathrm{PM}_{2.5}=$ & 11,7159 & $+4,4579 \mathrm{R}_{1}$ & & & $-2,7971 \mathrm{R}_{4}$ & & 0,7709 & 2,5410 \\
\hline 9 & $\mathrm{PM}_{2.5}=$ & 11,7696 & $+2,2091 \mathrm{R}_{1}$ & & & & $+0,7105 \mathrm{R}_{5}$ & 0,7546 & 2,6298 \\
\hline 10 & $\mathrm{PM}_{2.5}=$ & 15,6570 & & $+3,0258 \mathrm{R}_{2}$ & $-0,8116 \mathrm{R}_{3}$ & & & 0,7458 & 2,6762 \\
\hline 11 & $\mathrm{PM}_{2.5}=$ & 15,5774 & & $+5,2458 \mathrm{R}_{2}$ & & $-4,1752 \mathrm{R}_{4}$ & & 0,7830 & 2,4725 \\
\hline 12 & $\mathrm{PM}_{2.5}=$ & 12,9128 & & $+2,0466 \mathrm{R}_{2}$ & & & $+0,9824 \mathrm{R}_{5}$ & 0,7590 & 2,6058 \\
\hline
\end{tabular}




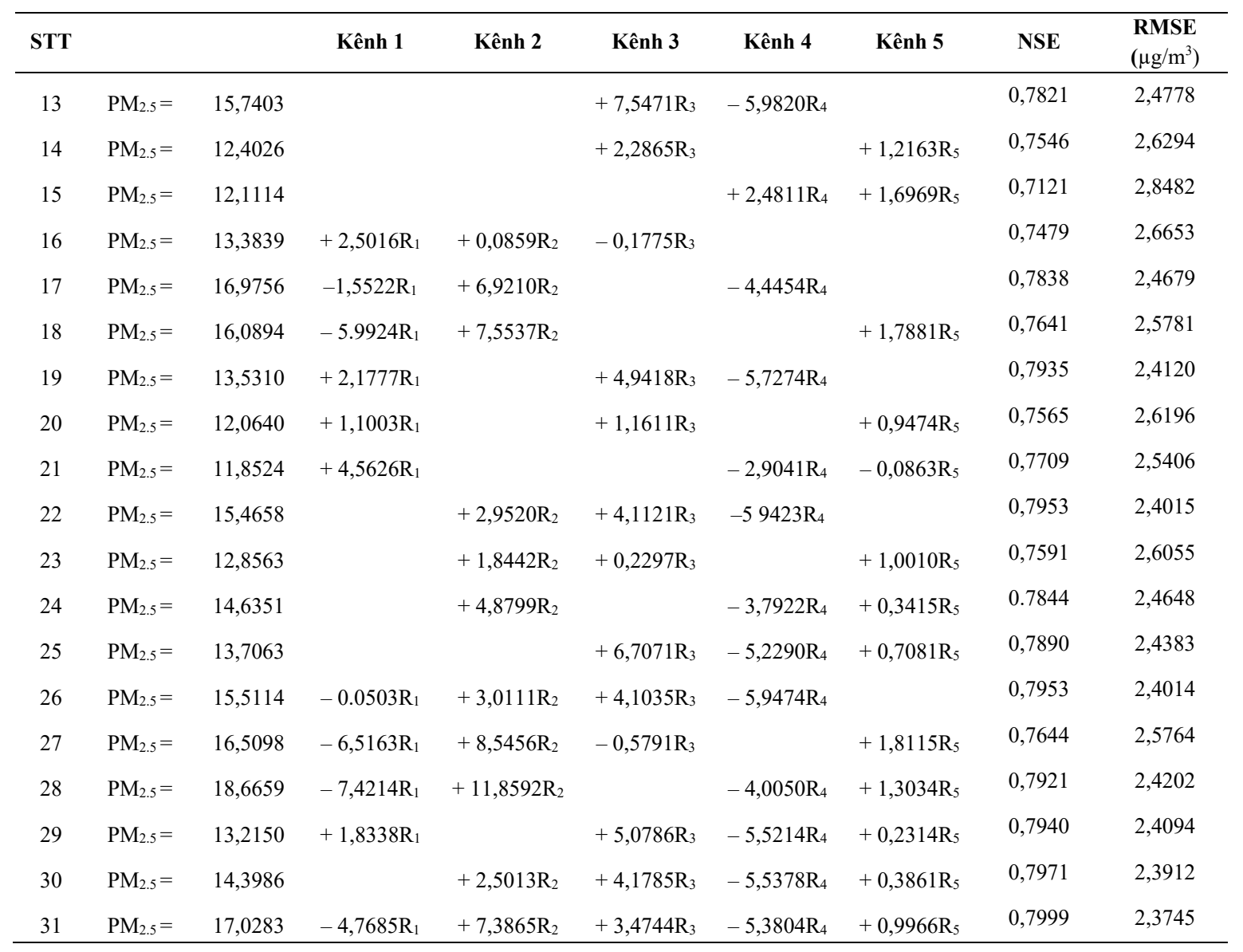

Trong đó phương trình số 31 cho kết quả hệ số hiệu quả mô hình NSE = 0,7999 (lớn hơn $0,75)$ lớn nhất, cho thấy hiệu quả mô hình tốt. Nghiên cứu cũng xem xét các thông số của mô hình phương trình (31) trong Bảng 5.

Bảng 5. Bảng thống kê hồi quy.

\begin{tabular}{cccc}
\hline $\mathbf{R}$ & $\mathbf{R}^{\mathbf{2}}$ & $\mathbf{R}^{\mathbf{2}}$ hiệu chỉnh & Sai số chuẩn \\
\hline 0,894376262 & 0,799908898 & 0,688747174 & 3,065422667 \\
\hline
\end{tabular}

Độ biến động của mô hình phương trình (31) được thể hiện trong Bảng 6.

Bảng 6. Bảng ANOVA.

\begin{tabular}{|c|c|c|c|c|c|}
\hline & df & SS & MS & $\mathbf{F}$ & Significance F \\
\hline Hồi quy & 5 & 338,0928526 & 67,61857 & 7,1959023 & 0,005676898 \\
\hline Dư & 9 & 84,57134517 & 9,396816 & & \\
\hline Tổng & 14 & 422,6641977 & & & \\
\hline
\end{tabular}

Trên cơ sở đó, phương trình (31) được sử dụng để thành lập bản đồ phân bố bụi $\mathrm{PM}_{2.5}$ cho khu vực nội thành của Tp. HCM. Phương trình này được viết như sau:

$$
\mathrm{PM}_{2.5}=17,0283-4,7685 \mathrm{R}_{1}+7,3865 \mathrm{R}_{2}+3,4744 \mathrm{R}_{3}-5,3804 \mathrm{R}_{4}+0,9966 \mathrm{R}_{5}
$$

3.2. Đánh giá nồng độ bụi PM2.5 khu vục nghiên cứu tại một số thời điểm giai đoạn 20152020

Nồng độ bụi $\mathrm{PM}_{2.5}$ trên khu vực nội thành TP. HCM tại một số thời điểm giai đoạn 20152020 được thể hiện trên Hình 3. 


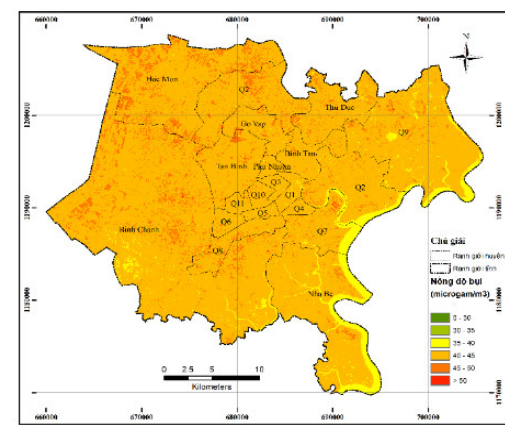

24/01/2015

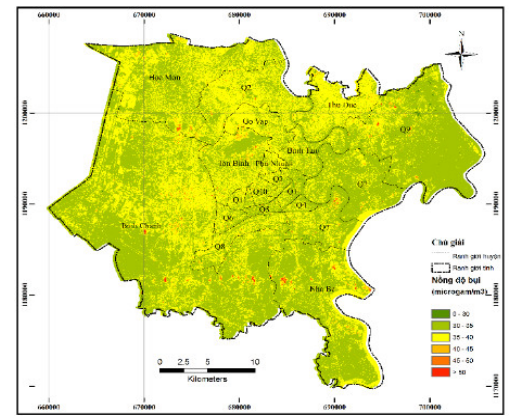

29/3/2015

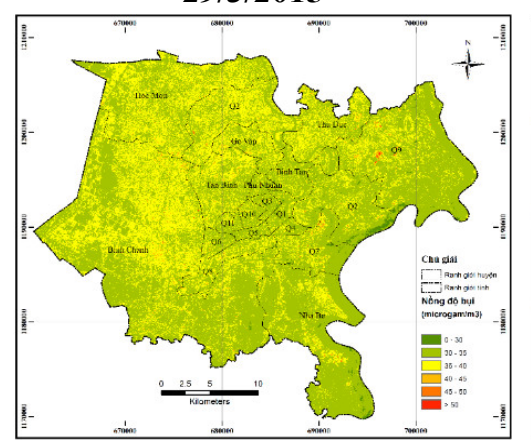

$14 / 02 / 2017$

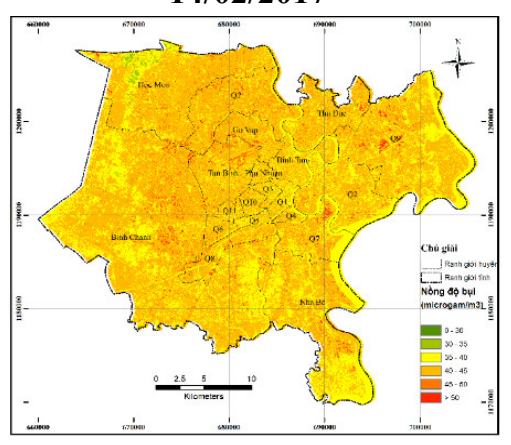

$02 / 12 / 2018$

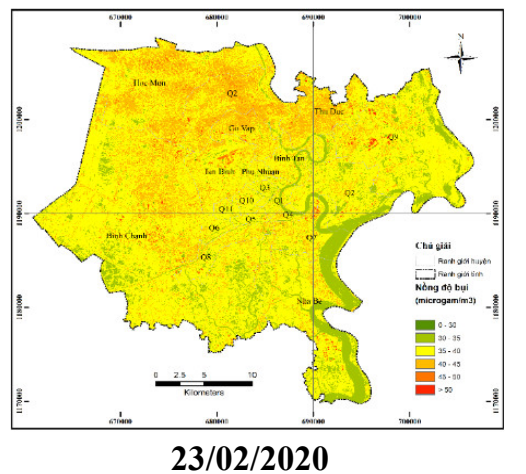

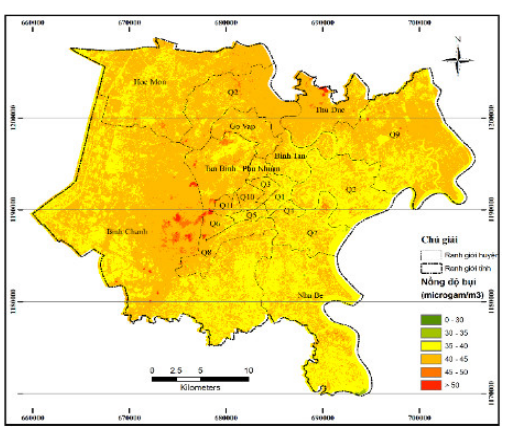

09/02/2015

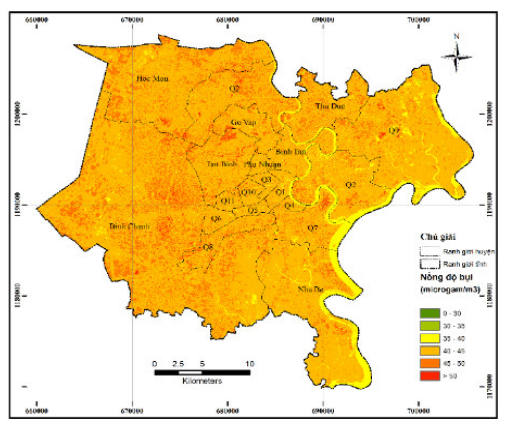

11/01/2016

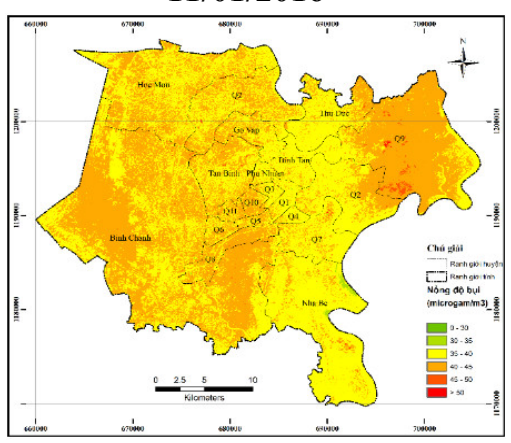

01/3/2017

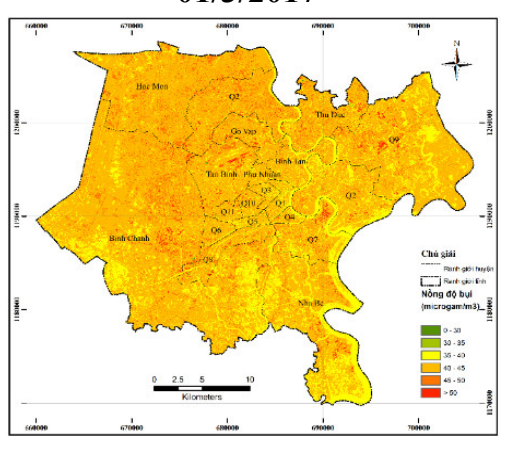

$19 / 01 / 2019$

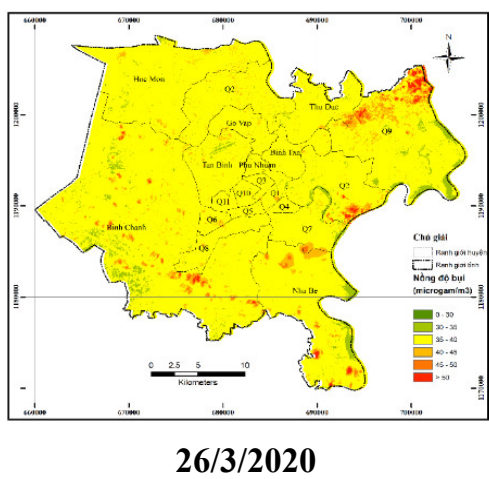

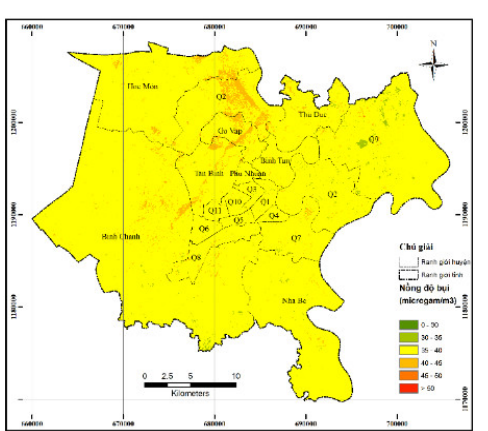

$13 / 3 / 2015$

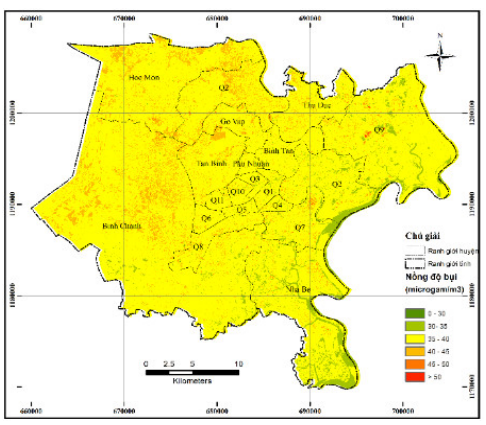

28/02/2016

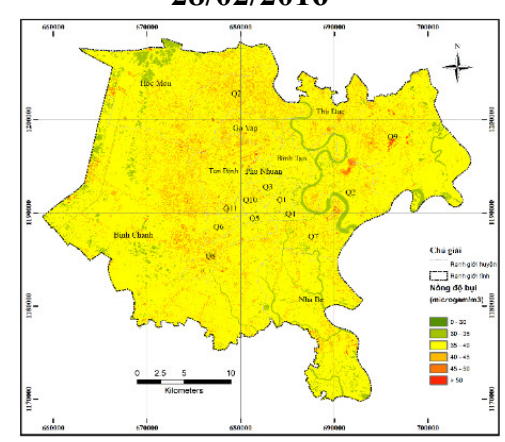

$31 / 10 / 2018$

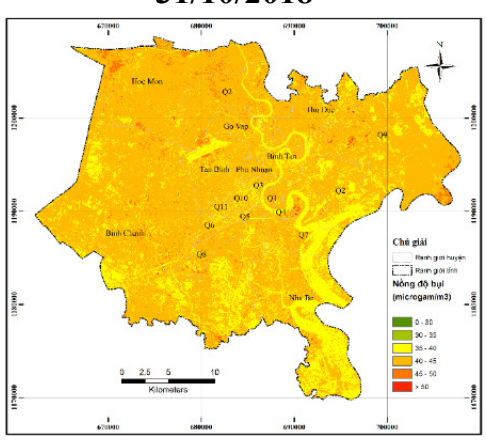

07/02/2020

\section{Chú thích}

Nồng độ bụi $\mu \mathrm{g} / \mathrm{m} 3$

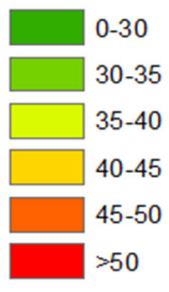

Hình 5. Bản đồ phân bố nồng độ $\mathrm{PM}_{2.5}$ tại một số thời điểm giai đoạn 2015-2020. 
Qua các thời điểm khác nhau, kết quả cho thấy bụi $\mathrm{PM}_{2.5}$ không phân bố điểm mà phân bố theo diện rộng. Đồng thời, kết quả bụi được ghi nhận trong khoảng thời gian từ 9 đên 10 giờ sáng và nồng độ bụi trung bình nằm ở mức cao (phần lớn tại các thời điểm ghi nhận, nồng độ bụi đều trên $30 \mu \mathrm{g} / \mathrm{m}^{3}$ ). Thành phố Hồ Chí Minh hiện có trên 8 triệu phương tiện giao thông (2019) với mật độ lớn, là một nguồn tạo ra lượng lớn bụi $\mathrm{PM}_{2.5}$. Đồng thời, do khối lượng rất nhỏ nên bụi chịu ảnh hưởng bởi gió, do đó nó phân bố ở diện rộng trên toàn khu vực. Điều này cũng được thể hiện trong nghiên cứu [21] cho địa bàn thành phố Hồ Chí Minh, được giải thích do hoạt động giao thông trên các tuyến đường chính, đặc biệt vào giờ cao điểm và mật độ các cơ sở hạ tầng lớn. [22] nghiên cứu tại thành phố Hà Nội cũng cho kết quả cao trong khoảng từ 6 đến 10 giờ với sự đóng góp từ nguồn cục bộ.

Bản đồ phân bố bụi vào ngày $31 / 10 / 2018$ cho thấy lượng bụi vào thời điểm này nằm ở mức thấp, có thể giải thích do vừa kết thúc mùa mưa nên một phần lớn bụi theo nước mưa lắng đọng xuống bề mặt đất, hàm lượng bụi tập trung ở mức $38 \mu \mathrm{g} / \mathrm{m}^{3}$. Các thời điểm ghi nhận được vào tháng 1 ở các năm đều cho thấy nồng độ bụi ở mức cao: kết quả ngày $24 / 01 / 2015$, nồng độ bụi $\mathrm{PM}_{2.5}$ cao trên toàn khu vực nghiên cứu, từ trên $40 \mu \mathrm{g} / \mathrm{m}^{3}$ lên đến gần $50 \mu \mathrm{g} / \mathrm{m}^{3}$, trong đó phổ biến nhất nằm trong khoảng $42-43 \mu \mathrm{g} / \mathrm{m}^{3}$. Điều này được thể hiện tương tự trong kết quả ngày 11/01/2016 và ngày 19/01/2019. Trong khi đó, một số thời điểm ghi nhận vào cuối tháng 3 , nồng độ bụi $\mathrm{PM}_{2.5}$ nằm ở mức thấp hơn: ngày 29/03/2015 (nồng độ bụi nằm dưới mức $30 \mu \mathrm{g} / \mathrm{m}^{3}$ ) và $26 / 03 / 2020$ (nồng độ bụi vào khoảng $35 \mu \mathrm{g} / \mathrm{m}^{3}$ ).

Tại các thời điểm ghi nhận được, nồng độ bụi có sự phân bố khác nhau giữa các khu vực trên địa bàn thành phố. Các khu vực thường xuyên ghi nhận kết quả nồng độ bụi cao hơn các khu vực khác bao gồm: khu vực Bình Chánh, Hóc Môn, khu vực giáp Củ Chi (phía Bắc), còn khu vực phía Nam-giáp với Cần Giờ, có nồng độ thấp hơn.

\section{Kết luận}

Nghiên cứu đã thực hiện xây dựng bản đồ phân bố bụi $\mathrm{PM}_{2.5}$ trên địa bàn Tp. HCM tại một số thời điểm từ năm 2015-2020. Kết quả cho thấy, hệ số phản xạ khí quyển từ ảnh vệ tinh tương quan tốt với giá trị bụi đo từ quá trình quan trắc, có 4 trong số 5 cặp biến có hệ số tương quan trên 0.8 . Trên cơ sở đó, nghiên cứu đã xây dựng phương trình hồi quy để ước tính lượng bụi với phương trình tốt nhất là phương trình 5 biến với hệ số $\mathrm{R}^{2}=0,7999$ và giá trị sai số $\mathrm{RMSE}=2,3745 \mu \mathrm{g} / \mathrm{m}^{3}$. Từ dữ liệu không gian, nghiên cứu đã chỉ ra bụi $\mathrm{PM}_{2.5}$ phân bố theo diện rộng, trong đó nồng độ bụi ghi nhận được tại các thời điểm phần lớn đều nằm ở mức cao, đặc biệt tại các thời điểm rơi vào tháng 1 . Khu vực phía Bắc và Tây Bắc thường xuyên ghi nhận được ô nhiễm bụi $\mathrm{PM}_{2.5}$ cao, trong khi khu vực phía Nam và Đông Nam ít ô nhiê̂m hơn.

$\begin{array}{ll}\text { Các từ viết tắt } & \\ \text { AOD } & \text { Aerosol Optical Depth (Độ dày quang học sol khí) } \\ \text { AOT } & \text { Aerosol Optical Thickness (Độ dày quang học sol khí) } \\ \text { DOS } & \text { Dark Object Subtraction (Trừ đối tượng tối) } \\ \text { PM } & \text { Particular matter } \\ \text { STT } & \text { Số thứ tự } \\ \text { Tp. HCM } & \text { Thành phố Hồ Chí Minh }\end{array}$

Đóng góp của tác giả: T.Q.T., N.P.H., Đ.N.K. đóng góp trong việc thiết kế nghiên cứu và viết bản thảo. T.Q.T. đóng góp trong việc thu thập dữ liệu, tính toán và phân tích kết quả.

Lời cảm ơn: Nghiên cứu được tài trợ bởi Trường Đại học Khoa học Tự nhiên, ĐHQG-HCM thông qua đề tài có mã số T2019-31. Bên cạnh đó, nhóm tác giả gửi lời cám ơn đến nhóm nghiên cứu của PGS.TS. Tô Thị Hiền công tác tại Trường ĐH KHTN, ĐHQG-HCM đã cung cấp số liệu bụi $\mathrm{PM}_{2.5}$ thực đo để thực hiện nghiền cứu này. 
Lời cam đoan: Tập thể tác giả cam đoan bài báo này là công trình nghiên cứu của tập thể tác giả, chưa được công bố ở đâu, không được sao chép từ những nghiên cứu trước đây; không có sự tranh chấp lợi ích trong nhóm tác giả.

\section{Tài liệu tham khảo}

1. Salahuddin, M.M.; Ash'aari, Z.H. Application of Remote Sensing Instruments in Air Quality Monitoring in Malaysia. Pertanika J. Scholarly Res. Rev. 2017, 3, 93-112.

2. Li, Z.; Zhang, Y.; Shao, J.; Li, B.; Hong, J.; Liu, D.; Li, D.; Wei, P.; Li, W.; Li, L.; Zhang, F.; Guo, J.; Deng, Q.; Wang, B.; Cui, C.; Zhang, W.; Wang, Z.; Lv, Y.; Xu, H.; Chen, X.; Li, L.; Qie, L. Remote sensing of atmospheric particulate mass of dry $\mathrm{PM}_{2.5}$ near the ground: Method validation using groundbased measurements. Remote Sens. Environ. 2016, 173, 59-68.

3. Sreekanth, V.; Mahesh, B.; Niranjan, K. Satellite remote sensing of fine particulate air pollutants over Indian mega cities. Adv. Space Res. 2017, 60, 2268-2276.

4. Trang thông tin điện tử Cục bảo vệ Môi sinh Hoa Kỳ. (https://www.epa.gov/pmpollution/particulate-matter-pm-basics)

5. Pope, III C.A.; Burnett, R.T.; Thun, M.J.; et al. Lung cancer, cardiopulmonary mortality, and long-term exposure to fine particulate air pollution. J. Am. Med. Assoc. 2002, 287, 1132-1141.

6. Pope III, C.A.; Dockery, D.W. Health effects of fine particulate air pollution: lines that connect. J. Air Waste Manage. Assoc. 2006, 56, 709-742.

7. Cổng thông tin điện tử Văn phòng Ủy ban nhân dân thành phố: https://vpub.hochiminhcity.gov.vn/portal/KenhTin/Gioi-thieu-ve-thanh-pho.aspx

8. Trang thông tin điện tử Diễn đàn hợp tác đầu tư (http://diendanhoptacdautu.com/)

9. Nguyen, T.T.N.; Bui, H.Q.; Pham, H.V.; Luu, H.V.; Man, C.D.; Pham, H.N.; Le, H.T.; Nguyen, T.T. Particular matter concentration mapping from MODIS satellite data: a Vietnamese case study. Environ. Res. Lett. 2015, 10, 095016.

10. Changqing, L.; Ying, L.; Zibing, Y.; Alexis, K.H.L.; Chengcai, L.; Jimmy, C.H.F. Using satellite remote sensing data to estimate the high-resolution distribution of ground-level $\mathrm{PM}_{2.5}$. Remote Sens. Environ. 2015, 156, 117-128.

11. Siwei, L.; Everette, J.; Qilong, M.; Bangsheng, Y.; Ricardo, S.; Megan, K.P. Remote sensing of PM2.5 during cloudy and nighttime periodsusing ceilometer backscatter. Atmos. Meas. Tech. 2017, 10, 2093-2104.

12. Somvanshi, S.S.; Vashisht, A.; Chandra, U.; Kaushik, G. Delhi Air Pollution Modeling Using Remote Sensing Technique. Handbook of Environmental Materials Management 2019, 1-27.

13. Vân, T.T.; Khánh, N.P.; Bảo, H.D.X. Viễn thám độ dày quang học mô phỏng phân bố bụi PM10 khu vực nội thành thành phố Hồ Chí Minh. Tạp chí Khoa học ĐHQGHN: Các Khoa học Trái đất và Môi trương 2014, 30, 52-62.

14. Hùng, T.Đ.; Phong, D.H.; Tùng, H.T.; Anh, N.N.; Hà, L.P.; Hằng, N.T.M.; Phượng, N.N.K.; Đông, N.H. Úng dụng công nghệ GIS và vệ tinh giám sát thay đổi hàm lượng bụi $\mathrm{PM}_{2.5}$ ở miền Bắc Việt Nam (2000-2005-2010). Hội thảo Khoa học Quốc gia về khí tượng, Thủy văn, Môi trường và biến đổi khí hậu 2017, 476-482.

15. Cổng thông tin điện tử Chính phủ thành phố Hồ Chí Minh (ngày 09/11/2011): http://tphom.chinhphu.vn/dieu-kien-tu-nhien

16. Trang Sài Gòn giải phóng điện tử (ngày 09/11/2020): https://www.sggp.org.vn/luong-phuong-tien-giao-thong-giam-60-trong-thoigian-cach-ly-xa-hoi-656021.html

17. Trang web Cục khảo sát Địa chất Hoa Kỳ (2015-2020): https://www.usgs.gov/corescience-systems/nli/landsat/using-usgs-landsat-level-1-data-product 
18. Hien, T.T.; Chi, N.D.T.; Nguyen, N.T.; Vinh, L.X.; Takenaka, N.; Huy, D.H. Current Status of Fine Particulate Matter (PM2.5) in Vietnam's Most Populous City, Ho Chi Minh City. Aerosol Air Qual. Res. 2019, 19, 2239-2251.

19. Chavez, P.S. Image-based atmospheric corrections-revisited and improved. Photogramm. Eng. Remote Sens. 1996, 62, 1025-1035.

20. Nadzri, O.; Mohd, Z.M.J.; Lim, H.S. Estimating Particulate Matter Concentration over Arid Region Using Satellite Remote Sensing: A Case Study in Makkah, Saudi Arabia. Mod. Appl. Sci. 2010, 4, 131-142.

21. Vân, T.T.; Bảo, V.Q. Satellite data supporting to monitor air quality from $\mathrm{PM}_{2.5}$ indicator. Kỷ yếu Hội nghị: Nghiên cứu cơ bản trong "Khoa học Trái đất và Môi trường", 2019, 567-570.

22. Hai, C.D.; Oanh, N.T.K. Effects of local, regional meteorology and emission sources on mass and compositions of particulate matter in Hanoi. Atmos. Environ. 2013, 78, $105-112$.

23. Huy, D.H.; Chí, N.Đ.T.; Phú, N.L.S.; Hiền, T.T. Bụi $\mathrm{PM}_{2.5}$ ở Thành phố Hồ Chí Minh: Phân tích hiện trạng và quy luật biến đổi theo thời gian dựa trên số liệu đo liên tục 2013-2017. Tạp chí phát triển Khoa học \& Công nghệ: Khoa học tụ nhiên 2018, $2,130-137$.

\title{
Evaluating the distribution of PM2.5 in Ho Chi Minh City using remote sensing technology-some initial results
}

\author{
Tran Quang Tra ${ }^{1}$, Nguyen Phuc Hieu ${ }^{2}$, Dao Nguyen Khoi ${ }^{1, *}$ \\ ${ }^{1}$ Faculty of Environment, University of Science, VNU-HCM; tqtra@hcmus.edu.vn; \\ dnkhoi@hcmus.edu.vn \\ ${ }^{2}$ ERM Company, Ho Chi Minh City; phuchieu50@gmail.com
}

\begin{abstract}
Recently, air pollution from fine particulate matter $\left(\mathrm{PM}_{2.5}\right)$ becomes one of the biggest environmental problems in urban areas of developing countries, including Vietnam. Ho Chi Minh City, the economic center of Vietnam accounting for 23\% of the country's GDP (2019), has suffered from poor air quality due to recent growth in the industrial sector and vehicle emissions. The objective of this study was to assess the spatial distribution of $\mathrm{PM}_{2.5}$ concentration in Ho Chi Minh City in the period 2015-2020 using LANDSAT 8 OLI/TIRS data. In this study, atmosphere reflection value derived from satellite images and in-situ measured $\mathrm{PM}_{2.5}$ data were used to set a regression and correlation models to compute the $\mathrm{PM}_{2.5}$ concentration for the study area. The models showed a good performance in calculating $\mathrm{PM}_{2.5}$ concentration with $\mathrm{R}^{2}>0.79$ and $\mathrm{RMSE}=2.3745 \mu \mathrm{g} / \mathrm{m}^{3}$. On this basis, the spatial distribution of $\mathrm{PM}_{2.5}$ concentration was established to evaluate its distribution characteristic and identify the areas with high air pollution. The results will provide useful information for policymakers in local air quality management.
\end{abstract}

Keywords: $\mathrm{PM}_{2.5}$; Air pollution; Landsat 8; Ho Chi Minh City; Remote sensing. 